\title{
COMMENTARY
}

\section{Early and simple detection of diastolic dysfunction during weaning from mechanical ventilation}

\author{
Gorazd Voga* \\ See related research by Moschietto et al., http://ccforum.com/content/16/3/R81
}

\begin{abstract}
Weaning from mechanical ventilation imposes additional work on the cardiovascular system and can provoke or unmask left ventricular diastolic dysfunction with consecutive pulmonary edema or systolic dysfunction with inadequate increase of cardiac output and unsuccessful weaning. Echocardiography, which is increasingly used for hemodynamic assessment of critically ill patients, allows differentiation between systolic and diastolic failure. For various reasons, transthoracic echocardiographic assessment was limited to patients with good echo visibility and to those with sinus rhythm without excessive tachycardia. In these patients, often selected after unsuccessful weaning, echocardiographic findings were predictive for weaning failure of cardiac origin. In some studies, patients with various degrees of systolic dysfunction were included, making evaluation of the diastolic dysfunction to the weaning failure even more difficult. The recent study by Moschietto and coworkers included unselected patients and used very simple diastolic variables for assessment of diastolic function. They also included patients with atrial fibrillation and repeated echocardiographic examination only 10 minutes after starting a spontaneous breathing trial. The main finding was that weaning failure was not associated with systolic dysfunction but with diastolic dysfunction. By measuring simple and robust parameters for detection of diastolic dysfunction, the study was able to predict weaning failure in patients with sinus rhythm and atrial fibrillation as early as 10 minutes after beginning a spontaneous breathing trial. Further studies are necessary to determine whether appropriate treatment tailored according to the echocardiographic findings will result in successful weaning.
\end{abstract}

*Correspondence: gorazd.voga@guest.arnes.si Department for Intensive Internal Medicine, General Hospital Celje, Oblakova 5, 3000 Celje, Slovenia
Moschietto and coworkers performed a complete transthoracic echocardiographic examination just before and 10 minutes after starting a spontaneous breathing trial (SBT) in 68 nonselected patients, who were ventilated for more than 48 hours [1]. The aim of the study was to define the role of left ventricular (LV) systolic and diastolic function in weaning outcome.

Twenty out of 68 patients failed to wean. There was no difference in LV systolic function between both the failed and successful weaning groups, and systolic dysfunction (defined as LV ejection fraction $<50 \%$ ) was not related to weaning outcome. The ratio between the mitral Doppler inflow velocity (E wave) and the annular tissue Doppler velocity (Ea wave) measured either before or very early during the SBT was significantly higher in the group with weaning failure, indicating strong association of diastolic dysfunction due to impaired relaxation. An increased E/Ea ratio (>12.6 before SBT and $>14.5$ during SBT) predicted weaning failure in patients with sinus rhythm and atrial fibrillation with $60 \%$ and $75 \%$ sensitivity, respectively, and with $95.8 \%$ specificity. In the failed group, relaxation impairment (defined as Ea $<8 \mathrm{~cm} /$ second) was more pronounced and was not improved during SBT. On the contrary, LV relaxation was improved during SBT in the successful group (increase of Ea from 8 to $10 \mathrm{~cm} /$ second).

\section{Importance of diastolic failure}

LV diastolic failure has been systematically defined since 1998 [2,3]. This failure is responsible for more than $50 \%$ of heart failure and is related to the mortality of outpatients [3-5]. LV diastolic failure is characterized by decreased myocardial compliance for a variety of causes: coronary artery disease, myocardial hypertrophy and fibrosis, infiltrative diseases, age, acidosis and hypoxia. In critically ill patients, diastolic dysfunction has been largely underdiagnosed despite many factors that can impair left ventricular relaxation. By introducing echocardiography into the routine hemodynamic assessment, the condition becomes increasingly recognized - but the real impact on prognosis of critically ill patients is still not known. Additional exercise is well known to provoke 
or unmask the diastolic dysfunction [6]. The weaning process, which represents additional work for the cardiovascular system and increases the venous return and afterload at the same time, therefore represents a suitable scenario for development of diastolic failure.

The rapid development of pulmonary edema with massive increase of pulmonary artery occlusion pressure during unsuccessful weaning was described by Lemaire and coworkers in 1988 [7]. On the contrary, 10 years later Jubran and coworkers confirmed inadequate increase of cardiac output with decreased mixed venous oxygen saturation during weaning failure of cardiac origin [8]. Differentiation between systolic and diastolic failure is difficult, but is clinically important because of different therapeutic approaches.

\section{Diastolic failure and weaning from mechanical ventilation}

A couple of recent studies focused on recognition of LV diastolic dysfunction and failure during weaning from mechanical ventilation. In 17/39 selected patients who failed two consecutive SBTs, Lamia and coworkers confirmed elevation of the pulmonary artery occlusion pressure during the third weaning trial. It could be predicted accurately (sensitivity $82 \%$, specificity $91 \%$ ) by a combination of E/A $>0.95$ and $\mathrm{E} / \mathrm{Ea}>8.5$. The study included $20 \%$ of patients with depressed left ventricular systolic function [9].

Caille and coworkers studied hemodynamic changes in 117 nonselected patients [10]. Weaning failure occurred more often in patients with depressed systolic function. Before the SBT, signs of diastolic dysfunction (shorter deceleration time of $\mathrm{E}$ wave and higher $\mathrm{E} / \mathrm{Ea}$ ratio) were found in patients with LV ejection fraction $<35 \%$. In patients with LV ejection fraction $<50 \%$, signs of diastolic dysfunction (increased E/A ratio and decreased deceleration time of $\mathrm{E}$ wave) were observed during the SBT.

Papanikolaou and coworkers obtained standard mitral inflow analysis and additional Doppler echocardiographic variables before and during a SBT in 50 critically ill patients without obvious cardiac disease for assessment of LV diastolic function and filling pressures [11]. Twenty-three patients failed to wean and weaning failure was significantly associated with LV diastolic dysfunction.

In all of these studies, patients with atrial fibrillation were excluded. This omission limits considerably the applicability of echocardiography for detection of diastolic failure since the proportion of patients with atrial fibrillation is constantly increasing.

\section{Conclusion}

The fact that diastolic (dys)function could be assessed in patients also with atrial fibrillation in Moschietto and colleagues' study represents an important new finding.
The second important message is that diastolic function was assessed only by measurement of $\mathrm{E}$ and Ea waves. Both variables are very simple to obtain and their ratio represents a reproducible and robust measure of LV diastolic properties. Finally, the short interval between two measurements (10 minutes after starting the SBT) makes serial echocardiographic evaluation very close to continuous monitoring and allows detection of progressive diastolic dysfunction, which was an excellent predictor of weaning failure.

Being aware of the importance of LV diastolic dysfunction in the evolution of weaning failure, therefore, all one needs is to observe the patient for 15 minutes before and during the initial phase of a SBT and to perform two very basic transthoracic echocardiographic examination examinations. It remains to be investigated whether early proper treatment can improve the success of weaning.

\section{Abbreviations}

LV, left ventricular; SBT, spontaneous breathing trial.

\section{Competing interests}

The author declares that he has no competing interests.

Published: 6 July 2012

\section{References}

1. Moschietto S, Doyen D, Grech L, Dellamonica J, Hyvernat H, Bernardin G: Transthoracic echocardiography with Doppler tissue imaging predicts weaning failure from mechanical ventilation: evolution of the left ventricle relaxation rate during a spontaneous breathing trial is the key factor in weaning outcome. Crit Care 2012, 16:R81.

2. Paulus WJ, Brutsaert DL, Gillebert TC, Rademakers FE, Sys SU, Leite-Moreira AF, Hess OM, Jiang Z, Kaufmann P, Mandinov L, Matter C, Marino P, Gibson DG, Henein MY, Manolas J, Smiseth OA, Stugaard M, Hatle LK, Spirito P, Betocchi, Villari B, Goetzsche O, Shah AM, et al:: How to diagnose diastolic heart failure. Eur Heart J 1998, 19:990-1003.

3. Nagueh SF, Appleton CP, Gillebert TC Marino PN, Oh JK, Smiseth OA, Waggoner AD, Flachskampf FA, Pellikka PA, Evangelisa A: Recommendations for the evaluation of left ventricular diastolic function by echocardiography. Eur J Echocardiogr 2009, 10:165-193.

4. Owan TE, Hodge DO, Herges RM, Jacobsen SJ, Roger VL, Redfield MM: Trends in prevalence and outcome of heart failure with preserved ejection fraction. N Engl J Med 2006, 355:251-259.

5. Redfield MM, Jacobsen SJ, Burnett JC Jr, Mahoney DW, Bailey KR, Rodeheffer $\mathrm{RJ}$ : Burden of systolic and diastolic ventricular dysfunction in the community: appreciating the scope of the heart failure epidemic. JAMA 2003, 289:194-202

6. Ha JW, Oh JK, Pellikka PA, Ommen SR, Stussy VL, Bailey KR, Seward JB, Tajik AJ: Diastolic stress echocardiography: a novel noninvasive diagnostic test for diastolic dysfunction using supine bicycle exercise Doppler echocardiography. J Am Soc Echocardiogr 2005, 18:63-68.

7. Lemaire F, Teboul JL, Cinotti L, Giotto G, Abrouk F, Steg G, Macquin-Mavier I, Zapol WM: Acute left ventricular dysfunction during unsuccessful weaning from mechanical ventilation. Anesthesiology 1988, 69:171-179.

8. Jubran A, Mathru M, Dries D, Tobin MJ: Continuous recordings of mixed venous oxygen saturation during weaning from mechanical ventilation and the ramifications thereof. Am J Respir Crit Care Med 1998, 158:1763-1769.

9. Lamia B, Maizel J, Ochagavia A, Chemla D, Osman D, Richard C, Teboul JL: Echocardiographic diagnosis of pulmonary artery occlusion pressure elevation during weaning from mechanical ventilation. Crit Care Med 2009, 37:1696-1701

10. Caille V, Amiel JB, Charron C, Belliard G, Vieillard-Baron A, Vignon P. Echocardiography: a help in the weaning process? Crit Care 2010, 14:R120. 
Voga Critical Care 2012, 16:137

Page 3 of 3

http://ccforum.com/content/16/4/137

11. Papanikolaou J, Makris D, Saranteas D, Karakitsos D, Zintzaras E, Karabinis A, Kostopanagiotou G, Zakynthinos E: New insights into weaning from mechanical ventilation: left ventricular diastolic dysfunction is a key player. Intensive Care Med 2011, 37:1976-1985. doi:10.1186/cc11378

Cite this article as: Voga G: Early and simple detection of diastolic

dysfunction during weaning from mechanical ventilation. Critical Care 2012,

$16: 137$. 